\title{
Multidisciplinary Optimization of Life-Cycle Energy and Cost Using a BIM-Based Master Model
}

\author{
Marcus Sandberg *(i), Jani Mukkavaara $₫$, Farshid Shadram and Thomas Olofsson $₫$ \\ Construction Management and Building Technology, Department of Civil, \\ Environmental and Natural Resources Engineering, Luleå University of Technology, 97187 Luleå, Sweden; \\ jani.mukkavaara@ltu.se (J.M.); farshid.shadram@ltu.se (F.S.); thomas.olofsson@ltu.se (T.O.) \\ * Correspondence: marcus.sandberg@ltu.se; Tel.: +46-920-493-072
}

Received: 16 November 2018; Accepted: 4 January 2019; Published: 8 January 2019

\begin{abstract}
Virtual design tools and methods can aid in creating decision bases, but it is a challenge to balance all the trade-offs between different disciplines in building design. Optimization methods are at hand, but the question is how to connect and coordinate the updating of the domain models of each discipline and centralize the product definition into one source instead of having several unconnected product definitions. Building information modelling (BIM) features the idea of centralizing the product definition to a BIM-model and creating interoperability between models from different domains and previous research reports on different applications in a number of fields within construction. Recent research features BIM-based optimization, but there is still a question of knowing how to design a BIM-based process using neutral file formats to enable multidisciplinary optimization of life-cycle energy and cost. This paper proposes a framework for neutral BIM-based multidisciplinary optimization. The framework consists of (1) a centralized master model, from which different discipline-specific domain models are generated and evaluated; and (2) an optimization algorithm controlling the optimization loop. Based on the proposed framework, a prototype was developed and used in a case study of a Swedish multifamily residential building to test the framework's applicability in generating and optimizing multiple models based on the BIM-model. The prototype was developed to enhance the building's sustainability performance by optimizing the trade-off between the building's life-cycle energy (LCE) and life-cycle cost (LCC) when choosing material for the envelope. The results of the case study demonstrated the applicability of the framework and prototype in optimizing the trade-off between conflicting objectives, such as LCE and LCC, during the design process.
\end{abstract}

Keywords: BIM; multidisciplinary optimization; middleware; master model; house-building

\section{Introduction}

Traditional building design involves both architectural and engineering disciplines in an iterative process to find solutions to the requirements and needs imposed by clients and regulations on space, availability, structural integrity, cost, etc. [1]. The environmental impact from the built environment (energy use, global warming potential, waste, etc.) has put forward new sustainability requirements regarding the building's performance over its life-cycle, such as life-cycle energy (LCE) and life-cycle cost (LCC) [2]. This poses new challenges on the design process to coordinate several domain models from different disciplines in to optimize the performance and minimize the impact over a building's life-cycle. The lack of a neutral main product definition to control the evolution of different domain models, such as in the manufacturing industry [3], causes many design iterations in the building design process [4]. To coordinate the design progression based on multiple different domain models is 
time demanding and error-prone. Finding optimal designs in this kind of process is not probable and clients usually have to get accustomed to "good-enough" designs rather than optimal designs [5].

Finding optimal solutions calls for optimization and such techniques have been used for quite some time within specific disciplines in the architectural, engineering, and construction (AEC) industry. Early applications related to energy analysis during building design includes, for example, optimization of thermal performance [6]. Evins [7] notes that multi-objective optimization in building design has increased in popularity as computation power is increasing, but the challenge of assisting designers in applying optimization still remains. Díaz et al. [4] provide an overview of multidisciplinary design optimization in the AEC industry and evaluated two off-the-shelf building information modelling (BIM) tools, a parametric modelling tool, a process integration and design optimization tool, and two structural tools. From this evaluation, they highlighted challenges to manage parameterization, automation, and interoperability between different domain models. The wide area of BIM has worked with the interoperability challenges for several decades now.

\subsection{Building Information Modelling}

The uptake of BIM systems has been promoted by many governmental organizations as a means to improve the performance of the AEC industry [8]. However, the possibility to improve the performance of the design process comes back to issues of coordination and interoperability in distributed multidisciplinary environments [9]. This lack of interoperability between different domain models also hinders the search for optimal design solutions $[4,10,11]$. Today's BIM-systems have built-in functionality that can support interoperability and integration of different modelling domains using a linking mechanism through API (application programming interface)-calls, add-ins, and neutral file formats, like IFC (industry foundation classes). Within BIM, the idea of a centralized information repository heavily relies on the integration of separate domain systems joined via a central information hub using IFC as the standardized format for data exchange [12]. The idea of a centralized information repository is similar to the concept of master models [13].

Master models come from the manufacturing industry and are featured in some CAD-CAM (computer aided design-computer aided manufacturing) software, where the aim is, through parametric modelling, the creation of automatic links between a central master model and its sub-models. In the manufacturing industry context, master model approaches aim at creating a product definition that can be used for CAD, computer-aided manufacturing, computer-aided engineering, and other types of analyses. Every change in the product definition of the master model is automatically/semi-automatically propagated to all domain-specific models. One of the first uses of the master model concept was reported by Newell and Evans [14]. Since then, several researchers have elaborated the master model concept, e.g., Hoffman and Joan-Arinyo [15] give examples from the manufacturing industry and Mondero [16] from the AEC sector. However, these examples have semi-automated workflows whereas optimization requires fully automated workflows.

Sandberg et al. [3] presented a framework where fully automated design and analysis workflows can be created based on a master model, exemplified for jet-engine optimization. This master model contains a programmable automation module, API-calls, macros for geometry generation, and analysis model generation using an off-the-shelf CAD-CAE software and computing software (i.e., Matlab). The coding of the automation module, API-calls, and macros here represent what can be called a middleware [17] which works as a "glue" [18] in the system to enable the fully automated workflow needed for optimization. The middleware helps in generating parts of the models, starting analyses, changing design variables, etc.; in other words, it enables automation by providing the parts the commercial systems fall short of delivering. Within the AEC industry, visual programming languages (VPL) through software, such as Grasshopper or Dynamo, have been found useful for middleware implementations $[19,20]$. 


\subsection{BIM Applications Related to Life-Cycle Energy and Cost Evaluation in Building Design}

Research on BIM applications has been reported with different focuses. Han et al. [21] provided a review of tools for simulation-based decision support and highlighted the need for tools and more advanced techniques for the early building design. Lee et al. [22] used Autodesk Revit to calculate the embodied energy by adding life-cycle inventory data to the material database in Revit, creating a so-called green template. In this way, they avoided interoperability issues in the connection with other simulation models. However, the method is software dependent and lacks the optimization part. Liu et al. [23] used Autodesk Ecotect coupled to a developed system for particle swarm optimization to demonstrate how the trade-off between life-cycle cost (LCC) (construction and operation cost) and life-cycle carbon emission (LCCE) of buildings can be optimized. The presented strategy is based around a single analysis software (Ecotect) not including a general BIM authoring tool, such as Revit or ArchiCAD. Therefore, no master model was established and the issues of interoperability with analysis software was thus avoided. Hence, it is unclear how to expand the proposed method beyond the presented application.

Other researchers present work that uses BIM-tools integrated with building performance simulation (BPS) tools e.g., [20,24,25]: Kim et al. [24] presented a framework for the trade-off between energy efficiency and investment costs during a renovation. The framework is based on Revit and the Autodesk Green Building Studio and only features manual optimization. Asl et al. [20] demonstrated how BIM and VPL can be used to create optimization possibilities. Project information, geometry data, and thermal properties of construction materials (window size and material are design variables) were used to create an analytical energy model from the design model using the Revit API and the gbXML open schema. Autodesk Green Building Studio conducted the analysis. The Revit API together with Dynamo feeds the daylighting analysis with data and an Autodesk cloud service conducts the daylighting analysis. The article indicates that other domain simulation models could be added to the framework, mentioning structural modelling as being used in a separate industrial implementation. The article initially depicts the framework in general terms and it uses both software integrated functionality (between Revit and Green Building Studio) and neutral formats (gbXML). The framework could have been extended to also feature more generic geometric data transfer (using e.g., IFC) to allow for a wider range of analysis model domains beyond energy and daylight simulation (e.g., structural, fire, cost and planning). Flager et al. [25] introduced research based on the Digital Project BIM software and EnergyPlus. Digital Project has integrated structural analysis and the energy simulation is connected through VB (Visual Basic) and C++ code. Using industry standard data models for information exchange has been mentioned as a possible future work option.

Researchers have also presented frameworks that use neutral file formats to link BIM models with simulation models for energy related evaluation during building design, e.g., [26,27]: Ryu and Park [26] presented an LEED (Leadership in Energy and Environmental Design) simulation process based on Revit and the exporting of a gbXML file to FZKViewer for model assessment. HVAC-calculations were done in Revit. Zhang et al. [27] presented a software platform called Virtual Design Studio, which uses IFC, gbXML, and IDF to evaluate a number of different aspects, e.g., life-cycle cost analysis, HVAC and daylighting (EnergyPlus), and room space. Although the framework is based on neutral file formats, it also uses software specific models and optimization is not included.

\subsection{Research Gap, Aim, and Method}

Soust-Verdaguer et al. [28] promotes the potential of neutral file formats before software dependent integrated tools in the area of BIM-based life-cycle assessment of buildings. However, there are still questions regarding the use of BIM as a master model and the central repository of neutral design information to balance various discipline-specific requirements.

How to design a BIM-based process using neutral file formats to enable multidisciplinary optimization? 
Of the presented research, Liu et al. [23] and Asl et al. [20] enabled BIM-based optimization, although a BIM authoring tool is only included in [20]. Asl et al. [20] used the gbXML format, but other, more generic, neutral formats, such as IFC, were not included in the framework. The Zhang et al. [27] framework, based on neutral file formats, has a quite well-described logic for the components of the Virtual Design Studio and could theoretically be used to generate even more models than those described in their paper. However, optimization was not included and the question is how to automate the design and analysis workflow. Hence, the major aim of this study is to explore and demonstrate how multiple models can be generated based on a neutral BIM design in order to optimize the building performance and trade-off between conflicting design objectives, such as LCE and LCC.

The research design is comprised of problem identification, method development, method examination, and theory suggestion. During problem identification, the research gap was identified through literature reviews and building design challenges (e.g., how to evaluate LCE and LCC) were gathered through discussions with AEC practitioners. This problem was targeted in the method development through a parallel development of a prototype and a generic framework that illustrates and describes a conceptual model of the information flow and process composition. During method examination, the prototype was evaluated through a single case study. Method development and examination were iterated until satisfied. Finally, the developed methods were than analyzed in comparison with the existing research to identify similarities and contributions.

The proposed framework is presented in Section 2, the developed prototype in Section 3, and the case study in Section 4. Finally, Section 5 discusses the result and in Section 6, conclusions and limitations together with proposals for future research are presented.

\section{Framework}

This paper proposes a framework for performing multidisciplinary optimization of building design. The framework allows for the generation of multiple domain models based on the product definition containing a set of design variables and constraints in the master model. The automated generation and performance evaluation provide a possibility to identify optimal design solution(s) by coupling the variation of design variables to an optimization approach. Figure 1 shows an overview of the framework and the following sections describe the details of its components.

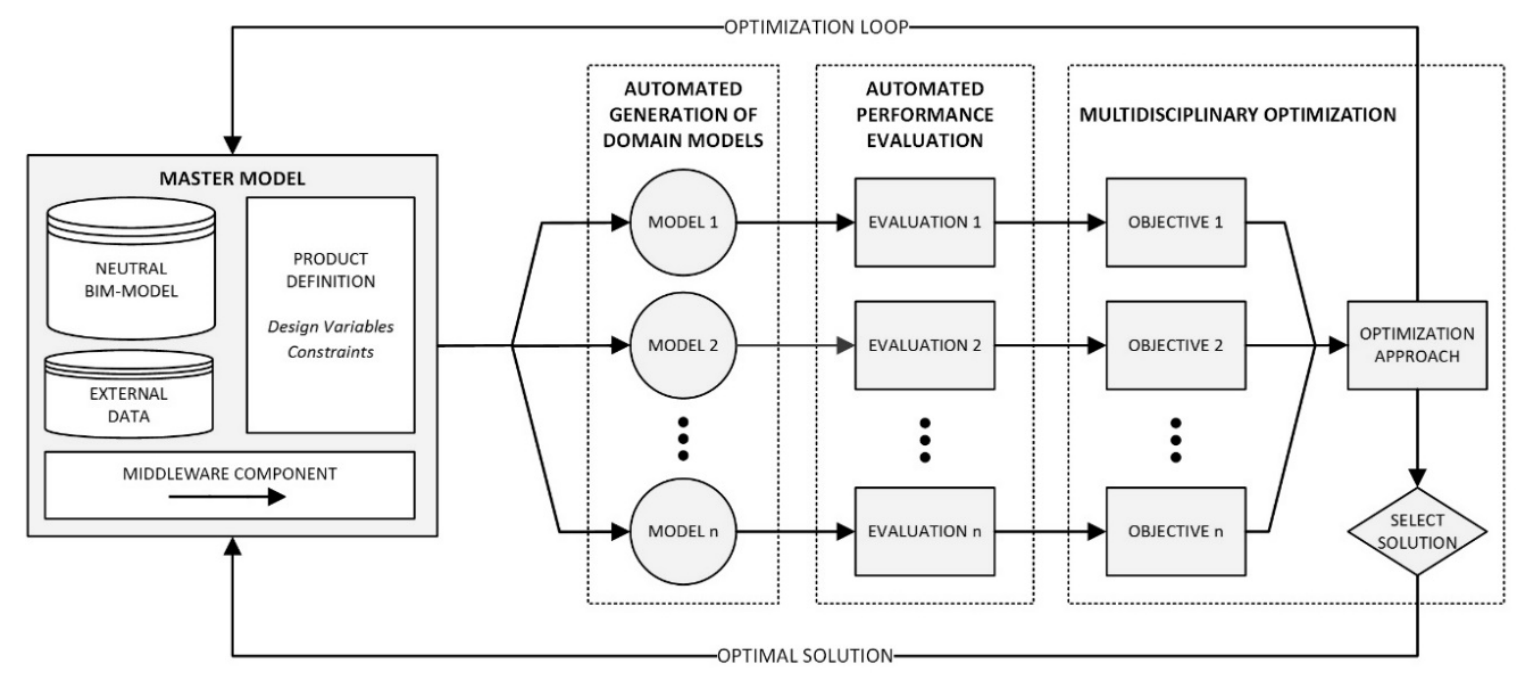

Figure 1. The proposed framework for enabling multi-disciplinary optimization.

\subsection{Master Model}

In the proposed framework, the master model is comprised of a neutral BIM model, external data, a product definition, and a middleware component. The aim of the master model is to provide a parametric product representation that can be used to automatically generate different domain models 
for performance evaluation and optimization. Each time the master model is changed, the alterations are also propagated to the domain models that are derived from the master [14].

The role of the neutral BIM model is to provide the primary means of input and output to and from the proposed framework, i.e., it acts as a central repository [12]. It is based on the idea that if a neutral format is used to express product data, it reduces the number of translators needed between the proposed framework and other applications [29], such as BIM authoring tools. The neutral BIM model comprises a comprehensive accumulation of information, including geometric representations and coupled attribute data. It contains a snapshot of the project at its current state and configuration. The purpose of the neutral BIM model is not to be the primary model passed through evaluations or optimization. The purpose is rather to contain a representation of (1) the initial design, and (2) the optimal solution (provided as the outcome of the optimization). The initial design from the neutral BIM model is a foundation for generating the different domain models in conjunction with the product definition. We can view the neutral BIM model as a temporarily static entity turned into a situational entity by application of the product definition and its solution space, i.e., all possible solutions that can be created within the valid (i.e., constraints permitting) value ranges of the design variables. When the optimization is complete and a solution has been chosen, the neutral BIM model contains the representation of the selected optimal solution.

Because optimization relies on the ability to change different parameters in search for better design alternatives, the use of a product definition is suggested in the framework. The product definition contains a collection of design variables and constraints. This collection provides a description of the product range and contains all the possible configurations that the product (i.e., building) can encompass. This is achieved by defining design variables that refer to what parts of a building's design that is subjected to the optimization in search for better design solutions. Examples of design variables include the material selection of thermal insulation, quantity (e.g., thickness) of materials, and component selection for different windows, which also is demonstrated in the prototype; however, future prototypes could also include: The building's orientation, load-bearing materials, etc. These design variables can be defined either as continuous or discrete, with upper and lower bounds. Continuous design variables are useful in defining, for example, the range of a material's thickness (or the rotation of a building), whilst discrete design variables are used when defining a given set of components (e.g., different type of materials for thermal insulation).

The product definition also contains constraints used to express limits on valid product configurations. Constraints are used in instances where the domains of the design variables are unable to express those limits. For example, constraints can be used to define the maximum thickness of a wall, whereas the multiple layers of the wall are defined through design variables. Constraints can also be set on the overall building, for instance, a constraint can be defined that only allows configurations where the operative temperature of the building falls within a given range. These types of constraints can be useful in order to ensure that the building complies with requirements and regulations.

When coupling the neutral BIM-model to the product definition, additional data might be required for the generation of domain models. The need for additional data comes from the introduction of the product range provided by the product definition. As the neutral BIM-model contains a snapshot of the current state of the building, it might lack some of the data that are necessary to evaluate different configurations. As such, the proposed framework includes external data sources in the master model. These can include, for example, a material properties' database, cost recipes, structural characteristics of construction materials, geographically dependent factors, such as climate data, etc. The primary goal of the external data is to provide domain information necessary for the performance evaluation of the domain model. For example, energy simulations need to have the thermal properties of each constituent material and these might not exist for all possible alternatives defined by the design variables within the neutral BIM-model. Additionally, external data can provide a source of data that is relevant only to the domain model, its simulations, analyses, or other processes, which is 
not necessary to store in the BIM model. The notation of "External", in this instance, refers to how the information is related to the neutral BIM model. As the neutral BIM model is regarded as the centralized repository for building information [12], accompanying data is regarded as external as it falls outside the boundaries of that centralized repository. External as such could imply that it is gathered from a website, database, spreadsheet, document, or any other entity deemed to be outside the scope of the centralized repository.

In order for the master model to enable optimization, an automated process is required for the generation of domain models, evaluation of those domain models, and execution of the optimization approach itself. Achieving this automated process includes managing the challenges of interoperability between domain models $[4,10,11]$. The master model in the proposed framework, therefore, includes a middleware component, whose purpose is to enable an automated process execution. The role of the middleware component is to facilitate communication and coordination [30]. In the proposed framework, this entails the implementation of functions to manage data and control [31]. Managing data is done by exchanging data from and to the neutral BIM model, external data, domain models, performance evaluation, and optimization. The middleware component does this whilst ensuring the compatibility of the exchanged data, by translating and transforming data according to the requirements of the process. Managing control is an additional layer in the middleware component that is responsible for coordinating the execution and interaction between the master model, domain models, performance evaluation, and optimization. Combined, it is the functions of the middleware component to manage the wide range of data and processes, which are required for multidisciplinary optimization, which allows for the automated execution of the optimization approach in the proposed framework.

\subsection{Domain Models and Performance Evaluation}

Based on the master model, multiple domain models can be automatically generated and examples of domain models primarily include models for energy simulation, life-cycle analysis, and life-cycle cost estimation among others. The domain models are generated based on a combination of data from the neutral BIM model, external data sources, and the product definition. The neutral BIM model provides the overall building representation and provides the basis from which individual domain models are generated. The overall representation is then transformed based on the product definition and additional data is appended to generate a domain model. For example, the representation found in the neutral BIM model can define a building's envelope and composition through various construction elements. In creating a domain model for energy simulation, the product definition can then be used to define the constituent materials of the building's envelope together with possible configurations. In the generation of domain models, external data is then used to complete the required data to represent a given domain model.

Each domain model is then used by the solver of each analysis software (e.g., energy, life-cycle cost). The analysis software evaluates the results of the domain model, i.e., the current configuration of the master model. Depending on the type of domain model and what evaluation is intended, the analysis software can include calculations, simulations, analyses, or other processes deemed necessary. The evaluation provides the objectives of the multidisciplinary optimization.

Automatically generating domain models and coupling them to a performance evaluation is one of the primary tasks of the middleware component in the master model. It is therefore necessary that, in the proposed framework, the middleware component is able to manage a wide range of systems, tools, and data that is required for this stage of the multidisciplinary optimization.

\subsection{Multidisciplinary Optimization}

When domain models have been generated and evaluated, they are passed through to multidisciplinary optimization. Here, optimization is the process of finding a function's maximum or minimum value when selected variables are subject to a set of constraints. From the performance evaluation, objectives are chosen for the optimization of the current building. An objective function 
is the commonly used name of the optimization function. If the optimization has only one objective function, it is mono-objective; however, if multiple objectives functions are used, the optimization process is multi-objective. The choice of the optimization process depends on the purpose of the study. For instance, if the purpose of the study is to minimize the building's energy use, then a mono-objective optimization can be adapted. During design, there are often objectives that conflict with each other. For such problems, the application of multi-objective optimization is beneficial to find the optimal solution(s) of design variables and thus solve the existing trade-off between conflicting objectives. In this framework, the application of different domain models provides the possibility to evaluate the impact of design variables on various objectives.

Usually, optimization is implemented by using mathematical algorithms along with an optimization method for selecting optimal solution(s). The algorithm executes design iterations to search for an optimal design in accordance with the specified design variables, constraints, and objectives, while the optimization method finds solutions corresponding to global or local optima from the executed design iterations. In the proposed framework, each iteration is a part of the optimization loop, where the optimization algorithm requests a new solution from the product definition, which is contained within the master model. This request then prompts the master model and its middleware component to propagate these changes to each domain model for evaluation. This provides new values for the objective functions that can be assessed by the optimization algorithm.

Generally, discontinuities can rise in the output of simulation engines and executed iterations by the optimization algorithm if discrete design variables are used [32]. Research indicates that the stochastic population-based algorithms (such as genetic algorithms (GA), evolutionary algorithms, particle swarm, and hybrid algorithms) are quite robust, with the discontinuities that may rise by the simulation engines when the discrete variables are involved in the optimization problem [32]. When the optimization is mono-objective, then the optimization method used to find solutions corresponding to optima from the executed design iterations is simple and focused on the solution(s) that provide a maximum/minimum objective function. However, for the multi-objective problems, two common approaches can be employed as the optimization method for finding the optimal solution from the iterations is carried out by an optimization algorithm. The first method is "scalarization", in which a weighting factor is assigned to each of the objective functions; the weighted objectives are then summed to produce just one objective function [33]. The second method, which is called "Pareto optimization", was proposed by Pareto [34] and examines a set of trade-off optimal solutions to determine the appropriate ones. A solution is non-dominated or Pareto optimal when there is no other feasible solution that enhances one objective without worsening at least another one. Each of these methods can be beneficial for finding the optimal solution(s) in the optimization of trade-off problems.

When the optimization is complete, the chosen optimal solution is sent back to the master model. The master model is responsible for updating the neutral BIM model to represent the optimal solution.

\section{Prototype}

A prototype was developed to test the applicability of the framework in a case study. The trade-off between a building's LCE and LCC was optimized to enhance the building's sustainability performance, see Figure 2. 


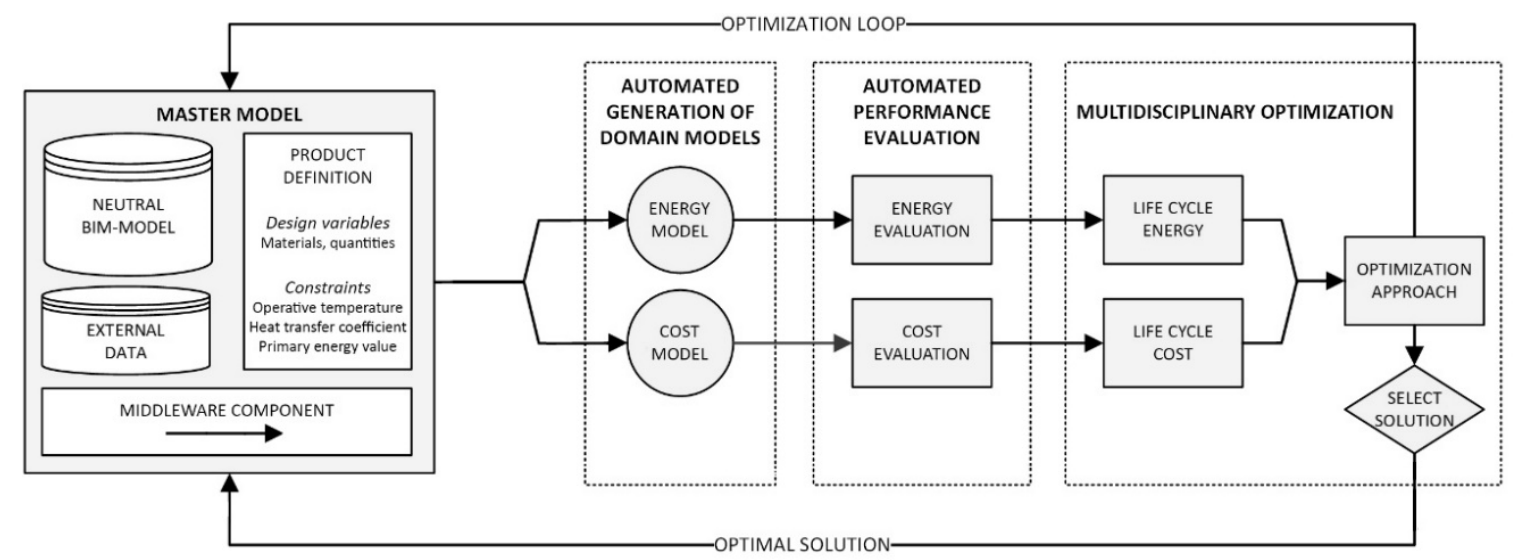

Figure 2. Outline of the developed prototype for the optimization of LCE and LCC.

The scope of the LCE and LCC optimization in this prototype is shown in Figure 3. The LCE includes the embodied energy required to produce the material and components in the building as well as the operational energy use for heating, cooling, and hot water demands of the building during its occupied period. Similarly, LCC is the sum of the present value of the investment cost for the above building materials and components as well as the operational costs for the operational energy use. Hence, the prototype does not account for the energy use and cost associated with the construction phase nor with the refurbishment and maintenance during its occupied period and end of life treatment.

The technologies, systems, and tools used for the developed prototype are detailed below. The methods and tools used for the LCE and LCC evaluation and optimization are presented in the next sub-sections.

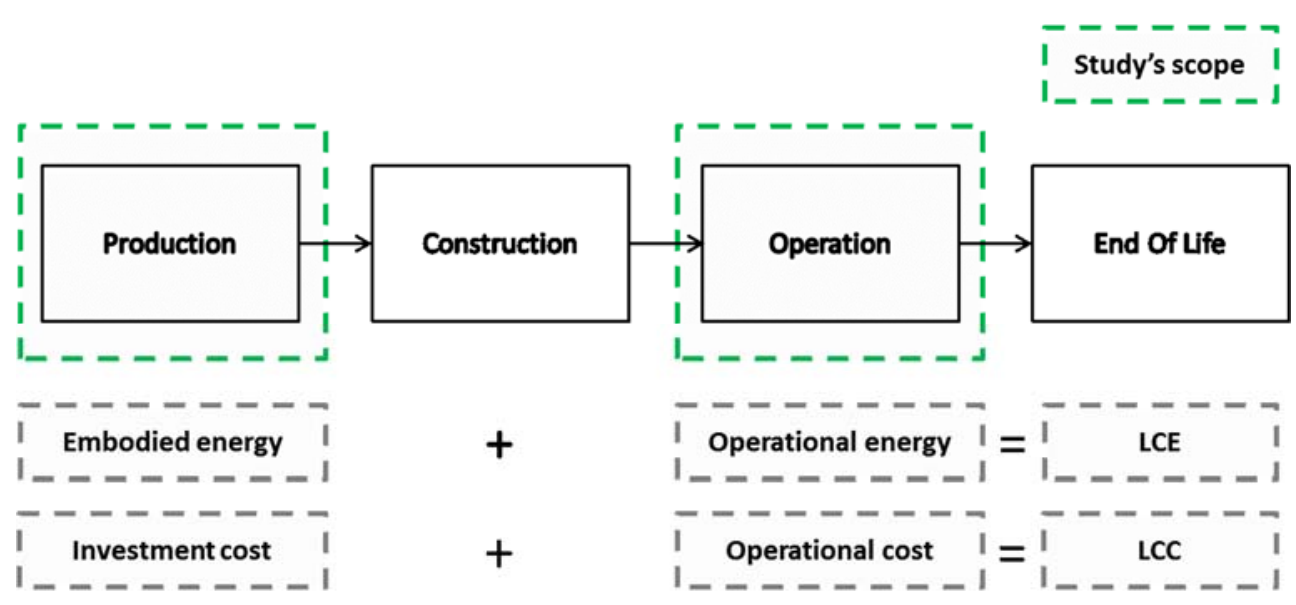

Figure 3. The scope of LCE and LCC in this prototype.

\subsection{Master Model}

The prototype used IFC as a neutral format for the BIM-model in the master model, as it is regarded as the primary interoperability solution between different software applications in the AEC industry [35]. The IFC-models were modelled with spaces representing different thermal zones and exported with second level space boundaries for the energy simulation. The prototype was developed and tested for IFC4 (industry foundation classes, release 4)-models exported from both Autodesk Revit and Graphisoft ArchiCAD.

A majority of the functionalities of the master model was implemented using Grasshopper [36], a visual programming add-on to Rhino 3D. Grasshopper acted as the middleware component for the master model and was responsible for importing and exporting data and controlling the sequence 
of executions in the multidisciplinary optimization loop. Grasshopper in itself was extended with additional functionality provided by GeometryGymIFC [37], Ladybug Tools [38], and Slingshot [39]. In order to exchange information with the BIM-model using the IFC format, custom nodes for Grasshopper were developed in C\# using GeometryGymIFC. These custom nodes allowed for the extraction of geometrical data from the IFC-models for the generation of domain models. Following a similar strategy to Ahn et al. [40], the second level space boundaries were extracted from the IFC-models and used as the primary geometrical representation for the energy simulation. The custom nodes also enabled the insertion of new data (materials and quantities) in the IFC-models for accepting the chosen solution provided by the multidisciplinary optimization.

For the provision of external data, a solution using MySQL as the database management system was included in the prototype. The developed database provided material properties for 90 commonly used construction materials and components. Each material and component entry in the database was populated with thermal conductivity, density, average lifespan, embodied energy, and material cost. Slingshot, an extension to Grasshopper, was used to retrieve the properties of individual materials and components from the MySQL database.

The product definition with discrete and continuous design variables was implemented using standard number sliders and lists nodes in Grasshopper. Furthermore, constraints were implemented using logic for less-than-or-equal-to or greater-than-or-equal-to nodes.

\subsection{Domain Models and Performance Evaluation}

Geometry and material types extracted from the IFC master BIM model and material properties from the MySQL database were combined to generate the energy and cost domain models for the performance evaluation of LCC and LCE use. The automated domain model generation for the domain model for energy was implemented using geometry from the IFC-model that was coupled with material data from the MySQL-database to provide a representation suitable for energy evaluation. For the domain model for cost, quantities of each construction element were extracted from the geometry provided by the IFC-model and coupled to cost data from the MySQL-database. A combination of mathematical calculations in Grasshopper and Ladybug Tools provides the support for the automated performance evaluations of the domain models using EnergyPlus [41] for operational energy use and material quantities from building elements for embodied energy use and life-cycle cost estimations.

\subsection{Multidisciplinary Optimization}

The prototype includes two objective functions, i.e., LCE and LCC. A multi-objective optimization algorithm was applied to minimize the trade-off between the two design objectives. The use of a genetic algorithm (GA), a stochastic population-based optimization technique, was considered to manage the discontinuities in the result that occurs when discrete design variables are applied [32]. Genetic algorithms (GA) have been reported to perform well in building optimization problems $[32,42,43]$ due to their (1) robustness in high simulation failure rates [32]; (2) capability to solve multi-objective trade-off problems [32]; (3) ability to handle discrete variables [32]; (4) strength in handling discontinuities [43]; and (5) capacity for performing parallel simulations in multi-processor computers [32]. Consequently, Octopus [44], a Pareto-based GA solver and add-in for Grasshopper, was selected as the optimization engine for the LCE/LCC prototype. A "Pareto optimization" solver provides a set of optimal and non-dominated solutions at the Pareto frontier [45]. The set of solutions provides an understanding of how different variables affect each of the objective functions (i.e., LCE and LCC) and gives the designer a choice to select the most suitable solution from the possible ones at the Pareto frontier.

The optimization problem introduced to Octopus is as follows:

$$
\operatorname{Min}\left\{f_{1}(\widetilde{x}), f_{2}(\widetilde{x})\right\}, \widetilde{x}=\left[x_{1}, x_{2}, \ldots, x_{n}\right]
$$


In Equation (1), $f_{1}$ is the first objective function (or LCE), $f_{2}$ is the second objective function (or LCC), $\widetilde{x}$ is a combination of design variables, and $x_{1}, x_{2}, \ldots, x_{n}$, and $n$ is the number of design variables subjected to the optimization.

$f_{1}$ (or a building's LCE) is estimated using the following equation (adapted from [46]):

$$
\begin{aligned}
f_{1}(\widetilde{x})=L C E= & \text { embodied }+ \text { operational energy } \\
& =\left(\sum_{n=1}^{r} E E_{n} \times \rho_{n} \times V_{n}\right)+\left(\sum_{i=1}^{u} E_{d e l, i} \times P E F_{i}\right) \times l
\end{aligned}
$$

where LCE (MJ) is the building's life-cycle energy (or first objective function), $E E_{n}(\mathrm{MJ} / \mathrm{kg}$ ) is the material's/component's embodied energy factor, $\rho_{n}\left(\mathrm{~kg} / \mathrm{m}^{3}\right)$ is the material's density, $V_{n}\left(\mathrm{~m}^{3}\right)$ is the quantity of material/component used in the building, $E_{d e l, i}(\mathrm{MJ})$ is the annual delivered energy used with the primary energy factor, $P E F_{i}$, from energy supply source $i$, and finally, $l$ (yrs) is the building's lifespan. The embodied energy factors are acquired from the Bath Inventory of Carbon and Energy (ICE) [47] except for some components, such as windows and doors, where the embodied energy factors used came from EPD databases [48,49]. The primary energy factors were obtained from [50,51].

$f_{2}$ (or the building's LCC) is estimated as the sum of the present value of investment costs for materials and components and the cost for operational energy use required during the building's occupied period. The following adapted equations [52] were used to estimate the building's LCC:

$$
\begin{aligned}
f_{2}(\widetilde{x})=L C C= & \text { investment cost }+ \text { operational cost } \\
& =\left(\sum_{n=1}^{r} I C_{n} \times V_{n}\right)+\left(\sum_{i=1}^{u} E_{d e l, i} \times P_{i}\right) \times d a_{e}
\end{aligned}
$$

where:

$$
d a_{e}=\frac{1-\left(1+r_{e}\right)^{l}}{r_{e}}
$$

and:

$$
r_{e}=\frac{r-e}{1+e}
$$

In Equation (3), LCC ( $€$ ) is the building's life-cycle cost (or second objective function), $I C_{n}\left(€ / \mathrm{m}^{3}\right)$ is the material's/component's investment cost, $V_{n}\left(\mathrm{~m}^{3}\right)$ is the quantity of each material/component in the building, $E_{d e l, i}(\mathrm{MJ})$ is the annual delivered energy use for the energy supply source $i$, and $P_{i}$ $(€ / \mathrm{MJ})$ is the energy price for the energy supply $i$. The equation for $d a_{e}$ and $r_{e}$, (Equations (4) and (5)) are the discount factor and the real interest rate, estimated by accounting for the escalation rate $(e)$ of the energy price, $r$ is the real interest rate, and $l$ (yrs) is the building's lifespan.

In addition, to ensure that the solutions found by the Pareto-based GA solver are feasible and satisfy the Swedish conditions and criteria [51], three constraints were specified on the objective functions. These constraints are as follows:

1. Operative temperature used to ensure that the solutions obtained by the optimization guarantee a minimum living zone operative temperature of $18^{\circ} \mathrm{C}$ [51].

2. Overall heat transfer coefficient of the building envelope $\left(U_{m}\right)$ to ensure that the overall heat transfer coefficient did not exceed the maximum allowed value $\left(\mathrm{Um}=0.4 \mathrm{~W} / \mathrm{m}^{2} \mathrm{~K}\right)$. The method for the calculation of the building's overall heat transfer coefficient was obtained from [51].

3. The annual primary energy use per $\mathrm{m}^{2}\left(\mathrm{~A}_{\text {temp }}\right)$ was used to ensure that the solutions found by the optimization guarantee the building's maximum allowed primary energy of $85 \mathrm{kWh} / \mathrm{m}^{2} \mathrm{yrs}$. The primary energy value was calculated using the guidelines specified in the Swedish national board of housing, building, and planning [51], and differs from the operational energy use.

These constraints were introduced into Octopus as "Boolean hard constraints" by adapting the built-in functions in Grasshopper for evaluating "less-than-or-equal-to" and "greater-than-or-equal-to" bounds. 


\section{Case Study}

The developed prototype was used in a case study to test the applicability of the framework as a decision support tool to optimize the trade-off between LCE and LCC. The case consisted of a multifamily residential building under construction in Uppsala, Sweden. The building has a $4374 \mathrm{~m}^{2}$ habitable area distributed into five and six floors, where the first floor is a basement. The total glazed area of the building is $256 \mathrm{~m}^{2}$ and the height of each floor is $2.8 \mathrm{~m}$. In this building district, heating is used to heat the building during its occupied period while electricity is used as the main energy source for household and operational electricity uses. Figure 4 shows the 3D model of the multifamily residential building in the case study.
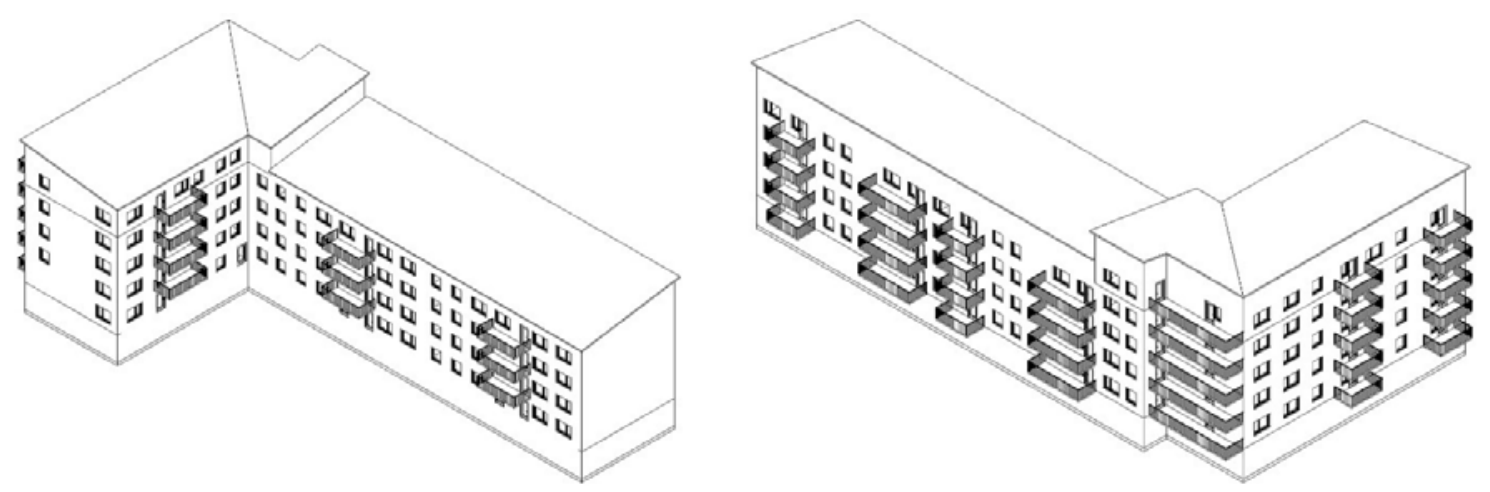

Figure 4. The multifamily residential building used in the case study.

The building's initial design, i.e., as-built design, was used in this case study to find the optimal solution(s) of windows, insulation materials, and their quantities that are used in the construction of the building envelope. The main reason that only the insulation materials were optimized beside the windows in this case study was due to the fact that the insulations were used in larger quantities and also had a greater impact on the building's LCE use and LCC. In total, seven design variables, of which four continuous and three discrete, were optimized in the case study. Tables 1-5 show the exterior building elements and components related to the initial design of the building as well as the continuous and discrete design variables considered in the optimization of the trade-off between LCE and LCC. Note that in Table 1, the variables can both be continuous and discrete, where the first one is related to different material thicknesses while the latter one is related to different material/component types.

Table 1. The exterior building elements and components related to the initial design of the building as well as the design variables considered in the optimization (Note that the constituent materials of the building elements are listed in order from interior to exterior).

\begin{tabular}{cccccc}
\hline $\begin{array}{c}\text { Building } \\
\text { Element }\end{array}$ & $\begin{array}{c}\text { Initial } \\
\text { Material/Component }\end{array}$ & $\begin{array}{c}\text { Initial } \\
\text { Thickness (m) }\end{array}$ & $\begin{array}{c}\text { Design } \\
\text { Variable }\end{array}$ & $\begin{array}{c}\text { Design } \\
\text { Variable } \\
\text { Number } \\
\text { (Continuous) }\end{array}$ & $\begin{array}{c}\text { Design } \\
\text { Variable } \\
\text { Number } \\
\text { (Discrete) }\end{array}$ \\
\hline Basement floor & $\begin{array}{c}\text { Oak } \\
\text { Concrete } \\
\text { Expanded }\end{array}$ & $\begin{array}{c}\text { Polystyrene (EPS) } \\
\text { Basement wall }\end{array}$ & 0.005 & No & \\
& $\begin{array}{c}\text { Concrete } \\
\text { Expanded }\end{array}$ & 0.1 & Yes & 1 \\
\hline
\end{tabular}


Table 1. Cont.

\begin{tabular}{cccccc}
\hline $\begin{array}{c}\text { Building } \\
\text { Element }\end{array}$ & $\begin{array}{c}\text { Initial } \\
\text { Material/Component }\end{array}$ & $\begin{array}{c}\text { Initial } \\
\text { Thickness (m) }\end{array}$ & $\begin{array}{c}\text { Design } \\
\text { Variable }\end{array}$ & $\begin{array}{c}\text { Design } \\
\text { Variable } \\
\text { Number } \\
\text { (Continuous) }\end{array}$ & $\begin{array}{c}\text { Design } \\
\text { Variable } \\
\text { Number } \\
\text { (Discrete) }\end{array}$ \\
\hline & Concrete & 0.08 & No & & \\
Exterior Wall & Polystyrene (EPS) & 0.280 & Yes & 3 & \\
& Light clinker concrete & 0.06 & No & & \\
& Plaster & 0.02 & No & & \\
& Concrete & 0.15 & No & & \\
Roof & Plastic foil & 0.0002 & No & & \\
& Cellulose & 0.6 & Yes & & \\
& Wood board & 0.022 & No & & \\
\hline Wir gap & 0.025 & No & & \\
\hline Window & Wood panel & 0.025 & No & & \\
\hline
\end{tabular}

Table 2. The continuous variables and their ranges considered in the case study.

\begin{tabular}{cccc}
\hline Design Variable Number (Continuous) & Lower Bound $(\mathbf{m})$ & Upper Bound $(\mathbf{m})$ & Variable Type \\
\hline 1 & 0.01 & 0.5 & Continuous \\
2 & 0.01 & 0.4 & Continuous \\
3 & 0.01 & 0.5 & Continuous \\
4 & 0.01 & 0.7 & Continuous \\
\hline
\end{tabular}

Table 3. The discrete variables and their ranges considered in the case study.

\begin{tabular}{ccccc}
\hline Design Variable Number (Discrete) & Index Min & Index Max & Table & Variable Type \\
\hline 5 & 0.01 & 0.5 & 4 & Discrete \\
6 & 0.01 & 0.4 & 4 & Discrete \\
7 & 0.01 & 0.5 & 5 & Discrete \\
\hline
\end{tabular}

Table 4. A list of the insulation materials considered as the discrete variables in this case study.

\begin{tabular}{|c|c|c|c|c|}
\hline Index Number & Material & $\begin{array}{c}\text { Thermal Conductivity } \\
(\mathrm{W} / \mathrm{mK})\end{array}$ & $\begin{array}{c}\text { Embodied } \\
\text { Energy (MJ/kg) }\end{array}$ & $\begin{array}{c}\text { Investment Cost } \\
\left(€ / \mathrm{m}^{3}\right)\end{array}$ \\
\hline 1 & PIR insulation & 0.028 & 102.1 & 229.9 \\
\hline 2 & EPS insulation & 0.035 & 88.6 & 171.7 \\
\hline 3 & Mineral wool & 0.039 & 16.6 & 133.4 \\
\hline 4 & Cellulose & 0.042 & 2.5 & 69.0 \\
\hline
\end{tabular}

Table 5. A list of the windows considered as the discrete variables in this case study.

\begin{tabular}{ccccc}
\hline Index Number & Window Type & $\begin{array}{c}\text { Thermal Conductivity } \\
(\mathbf{W} / \mathbf{m K})\end{array}$ & $\begin{array}{c}\text { Embodied Energy } \\
\mathbf{( M J} / \mathbf{k g})\end{array}$ & $\begin{array}{c}\text { Investment Cost } \\
\left(\boldsymbol{(} / \mathbf{m}^{\mathbf{2}}\right)\end{array}$ \\
\hline 1 & Double glazed & 1.3 & 1551.3 & 225.4 \\
2 & Triple glazed & 1.1 & 1989.6 & 255.6 \\
\hline
\end{tabular}

The parameters and constraints of the objective functions considered in the case study are illustrated in Table 6. These parameters and constraints are based on Swedish building codes and guidelines [51,53]. 
Table 6. Parameters and constraints on the objective functions considered in this case study.

\begin{tabular}{|c|c|c|}
\hline Parameters & Value & Source \\
\hline Building's lifespan (occupied period) & 50 yrs & \\
\hline Room's heating set point & $21^{\circ} \mathrm{C}$ & [53] \\
\hline Cooling & Turned off & \\
\hline Number of occupants & 0.028 occupants $/ \mathrm{m}^{2}$ & \\
\hline Mechanical ventilation (air flow) & $0.0002 \mathrm{~m}^{3} / \mathrm{s} \mathrm{m}^{2}$ & \\
\hline Ventilation recovery ratio (always on) & $75 \%$ & \\
\hline Infiltration rate & $0.000227 \mathrm{~m}^{3} /\left(\mathrm{s} \mathrm{m}^{2}\right.$ exterior surface $)$ & \\
\hline $\begin{array}{l}\text { Additional energy use and losses (e.g., plant losses, } \\
\text { distribution system losses, and thermal bridges) }\end{array}$ & $10 \%$ of the heating demand & \\
\hline Operational electricity for fans, pumps, etc. & $5 \mathrm{kWh} / \mathrm{m}^{2} \cdot \mathrm{yrs}$ & \\
\hline Real interest rate & $2 \%$ & [54] \\
\hline Energy escalation rate & $3 \%$ & \\
\hline $\begin{array}{l}\text { Minimum operative temperature (first constraint on } \\
\text { the objective functions) }\end{array}$ & $18^{\circ} \mathrm{C}$ & [51] \\
\hline $\begin{array}{l}\text { Maximum overall heat transfer coefficient of the } \\
\text { building (second constraint on the objective functions) }\end{array}$ & $\mathrm{U}_{\mathrm{m}}=0.4 \mathrm{~W} / \mathrm{m}^{2} \mathrm{~K}$ & [51] \\
\hline $\begin{array}{l}\text { Maximum primary energy use (third constraint on the } \\
\text { objective functions) }\end{array}$ & $85 \mathrm{kWh} / \mathrm{m}^{2} \cdot \mathrm{yrs}$ & [51] \\
\hline
\end{tabular}

\subsection{Computational Efficiency and GA Parameters}

Optimization of the LCC/LCE trade-off was performed on a computer with a $3.4 \mathrm{GHz}$ Intel ${ }^{\circledR}$ Xeon ${ }^{\circledR}$ CPU, 64 GB RAM and running Microsoft Windows 7 as the operating system. On average, each simulation run took $20 \mathrm{~s}$. The following GA parameters were used: Maximum generations $=100$, population size $=50$, crossover rate $=0.8$, mutation probability $=0.1$, mutation rate $=0.5$, and elitism $=0.5$. The outcome (i.e., Pareto solutions) from the application of this set of GA parameters were compared with the outcome obtained using a maximum of 200 generations with the population size of 200. The obtained solutions from the 200/200 run were very similar to the Pareto solutions from the test run, with 100 generations and a population size of 50. Hence, the generated Pareto solution using a maximum of 100 generations and a population size of 50 were considered reliable.

\subsection{Results}

Figure 5 depicts all the feasible solutions that outperformed the initial design obtained from the multi-objective optimization of LCE versus LCC for the case study building located in Uppsala, Sweden. 


\section{LCC vs. LCE}

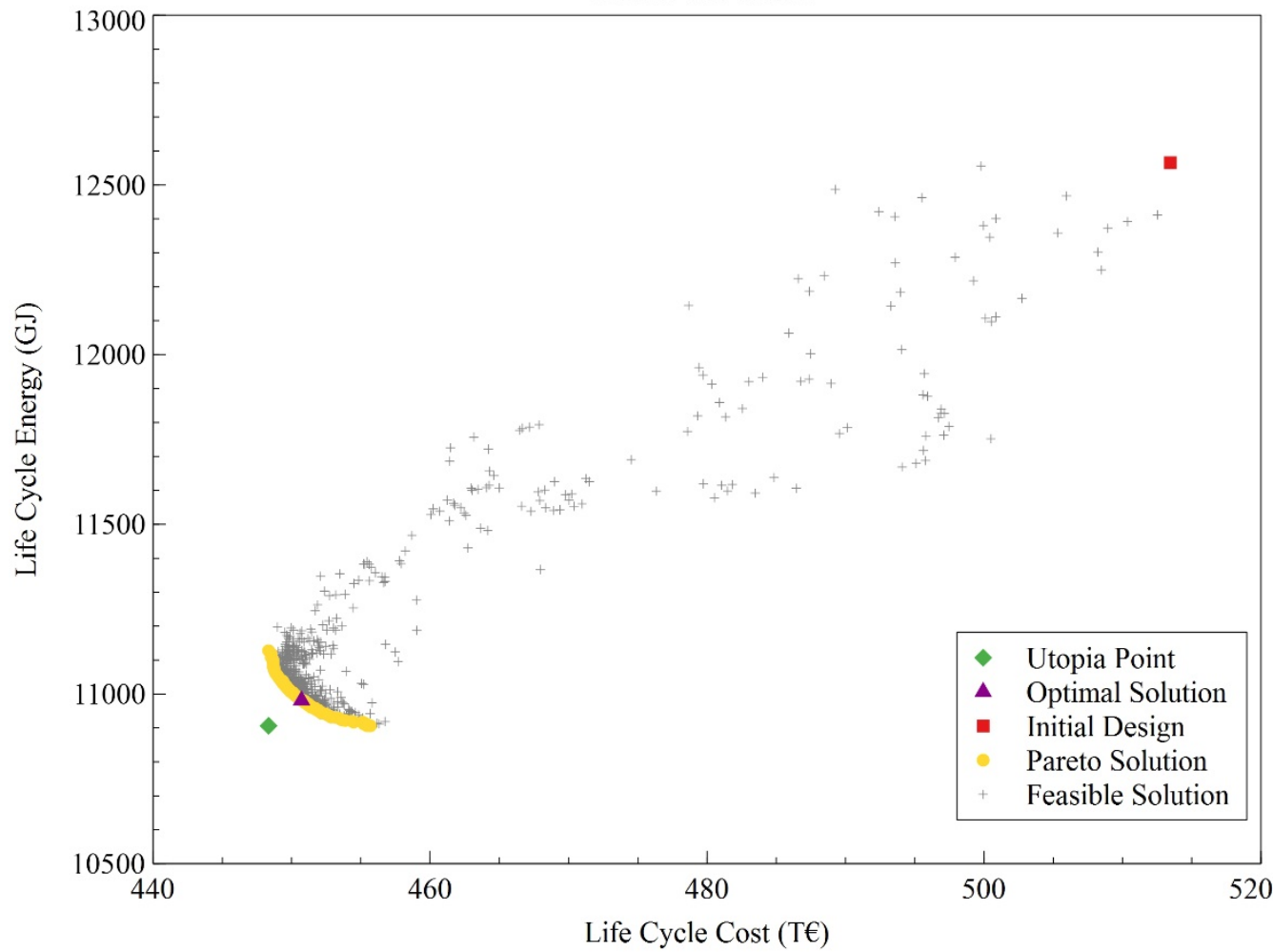

Figure 5. Scatter chart of feasible solutions, Pareto solutions, utopia point, initial design, and optimal solution, which outperforms the initial design obtained from optimization of the case study building (the results indicate LCE versus LCC assuming 50 years lifespan for the building).

The initial design shows the result of LCE versus LCC obtained, with the windows, materials, and their quantities used in the as-built design of the case study building. Pareto solutions depict non-dominated solutions, where no other feasible solutions exist that enhance an objective without worsening another. The utopia point that provides the lower bounds of Pareto solutions indicates an imaginary target that cannot be achieved, as there is a trade-off between LCE and LCC. Each of the Pareto solutions that outperform the initial design in terms of LCE and LCC has the potential to be selected as the optimal design solution. The optimal solution, the triangle in Figure 5, is the point on the Pareto front that is closest to the utopia point. The design variables for the optimal solutions are listed in Table 7. The LCE and LCC values of the optimal and initial designs and benefits of the optimization are shown in Table 8.

Table 7. The design variables of the optimal solution.

\begin{tabular}{cccccccc}
\hline Solution & Var. $\mathbf{1}(\mathrm{m})$ & Var. $\mathbf{2}(\mathrm{m})$ & Var. $\mathbf{3}(\mathrm{m})$ & Var. $\mathbf{4}(\mathrm{m})$ & Var. $\mathbf{5}$ & Var. $\mathbf{6}$ & Var. $\mathbf{7}$ \\
\hline Optimal solution & 0.09 & 0.09 & 0.35 & 0.69 & Mineral wool & Cellulose & Double glazed \\
\hline
\end{tabular}

Table 8. The objective function values of the optimal solution.

\begin{tabular}{ccccccc}
\hline Solution & $\begin{array}{c}\text { LCE of } \\
\text { Optimal } \\
\text { Solution } \\
\text { (GJ) }\end{array}$ & $\begin{array}{c}\text { LCC of } \\
\text { Optimal } \\
\text { Solution } \\
\text { (T€) }\end{array}$ & $\begin{array}{c}\text { LCE of } \\
\text { Initial } \\
\text { Design (GJ) }\end{array}$ & $\begin{array}{c}\text { LCC of } \\
\text { Initial } \\
\text { Design (T€) }\end{array}$ & $\begin{array}{c}\text { Benefit of } \\
\text { the Optimal } \\
\text { Solution in } \\
\text { Terms of } \\
\text { LCE (GJ) }\end{array}$ & $\begin{array}{c}\text { Benefit of } \\
\text { the Optimal } \\
\text { Solution in } \\
\text { Terms of } \\
\text { LCC (T€) }\end{array}$ \\
\hline $\begin{array}{l}\text { Optimal } \\
\text { solution }\end{array}$ & 10981.3 & 450.72 & 12656.3 & 513.46 & 1675.0 & 62.74 \\
\hline
\end{tabular}


As it can be observed in Table 8, the optimal solution could yield savings of 1675.0 (GJ) LCE and 62.74 (T€) LCC relative to the initial design. This amount of savings is equivalent to $13 \%$ of the reference building's LCE use and 12\% of its LCC for the building envelope, respectively. Additionally, the analysis of the building envelope indicated that the strongest benefit on LCE use and LCC among all building elements could be achieved by thickening the roof insulation, followed by thickening the exterior walls' insulation (see Table 7). The results thus demonstrate the applicability of the proposed framework and developed prototype in enhancing the design of a building's sustainability performance by optimizing the trade-off between LCE and LCC.

\section{Discussion}

The proposed framework for multidisciplinary design optimization is based on the master model concept [3,14-16] and adds the automated design and analysis workflows for the AEC industry to the theory of master models. Changes in the master automatically propagate to derived domain models for performance evaluation of defined design objectives. The automation of the design and analysis workflow provides the foundation for the optimization loop. To enable the automated workflows, the use of a middleware component within the master model of the framework is a key feature to provide the functionalities necessary and to resolve the challenges of interoperability between the required sets of systems, tools, and data.

In comparison with proposals for BIM-based optimization, Asl et al. [20] and Liu et al. [23], the proposed framework contributes with the definition of a master model to provide a parametric product representation that can be used to automatically generate different domain models for optimization. The presented prototype includes similar design variables as Asl et al. [20], i.e., material selection. Other proposals, such as the "Virtual Design Studio" framework presented by Zhang et al. [27], did not include automated workflows and optimization of multi-disciplinary design objectives.

The decision to use a neutral (IFC-based) BIM representation of the current "master" design was to facilitate the use of a wider range of domain analysis and modeling tools [28]. The description of the product definition in the master model is of special importance as it further details how design variables and constraints are handled in connection to the master BIM-model and generation of domain models. Extending the master model with a middleware component responsible for process automation and data exchange provides the integrated functionality that can be found in proprietary systems, such as the Autodesk suite with Revit as BIM-authoring tool, Ecotect and Green Building Studio for energy modelling, etc. However, Soust-Verdaguer et al. [28] state that neutral file formats can allow for a more complete assessment during the building life-cycle compared to those assessments that are enabled by integrated systems. However, sometimes, for special cases, there might be possibilities to harvest the benefits of both approaches, e.g., Asl et al. [20] used both the integrated functionality of Revit and the Green Building studio as well as using the open format gbXML for data exchange.

The prototype of the presented framework was implemented using a number of selected software components, e.g., Grasshopper and EnergyPlus. Being a general framework means that using other software also works for prototype implementations. However, it might not be possible to realize exactly the same functionality with another software setup. This also applies to the inclusion of additional objectives, software, and middleware components to create fully automatic workflows. The framework, however, presents the required processes and information flow on a general level that is used regardless of the software implementation.

The optimization framework is more suited for use in design phases on an overarching building level, where a manual search for optimal solutions among possible combinations of many variables is impossible to carry out. The framework can also trigger a change of work practices in order to enable domain representatives from multiple disciplines (users of the framework) to evaluate what-if-scenarios together. That would give the team the possibility to make fast decisions and find "Pareto" optimal candidates of the building design. However, there is a need for strategies on 
how to decide what solution to use since the number of Pareto solutions can be large. With such decision strategies, optimization could have an even larger impact on building design practices [7]. The optimization framework can also be applied to building sub-systems.

\section{Conclusions}

The paper presents a framework for multidisciplinary performance optimization to support the evaluation of LCE and LCC during building design. The framework consists of (1) a centralized master model, from which different discipline-specific domain models are generated and evaluated; and (2) an optimization algorithm controlling the optimization loop. The main conclusions from this work include:

- Creating a master model with functionality to enable automated workflows is an enabler for BIM-based optimization and this paper contributes to explaining how this can be done.

- In order to work with a neutral file format (such as IFC), the master model can be implemented with a product definition containing the design variables (continuous or discrete) that demarcate the solution space to be investigated and the constraints providing the limits for valid solutions, external data not available in the master BIM, but necessary for the generation of domain models, and a middleware component that provides the functionality and data exchanges necessary to automate the required workflows and enable multidisciplinary optimization.

The applicability of the framework was tested by developing a prototype and using it in a case study of a Swedish multifamily residential building. The prototype was developed to enhance economic and environmental dimensions of buildings' performance by optimizing the trade-off between LCE use and LCC for different selections of insulations and windows. A stochastic population-based genetic algorithm was selected using a Pareto optimization method due to the ability to solve multi-objective trade-off problems and its robustness with discontinuities that may arise when discrete variables are involved.

The results of the case study demonstrated the applicability of the framework and the prototype in solving the LCE/LCC trade-off by generating multiple models based on the BIM-model and linking it to a multi-objective genetic algorithm. As a result of this, the LCE and the LCC of a multifamily residential building in the case study could be reduced by more than $12 \%$.

\subsection{Limitation}

The scope of LCE and LCC in the case study only accounted for material and components in the building envelope and the operational primary energy use and cost for heating, cooling, and hot water demand, excluding the use and costs related to the household electricity. In addition, the primary energy use and investment costs caused by the production of materials related to mechanical systems, such as heating, ventilation, and air conditioning systems, were excluded in the case study mainly due to lack of appropriate data for the embodied energy factors. However, as a simplification, it was assumed that identical mechanical systems would be required in all the solutions so that the mechanical systems would not have any considerable impact on the comparison between the initial and optimal solution.

Furthermore, as the LCC was optimized with respect to its trade-off with LCE in this study, it was necessary that the same system boundary (or scope) was used for both of the life-cycle analyses (i.e., LCE and LCC) in order to create comparable results. As an investigation of the energy use associated with construction processes (i.e., installation work on site) was out of the scope of this study, the cost of this work was not included. Therefore, further research is required to expand the findings and account for energy use and costs of the construction processes.

The developed framework and prototype was tested in a single case study, which is why the conclusions drawn are limited to this specific case study context. A multi case study would have generated even more data to use when analyzing the contribution of the proposed methods. 
Developing more prototypes based on the same framework would also benefit the evaluation of the framework.

\subsection{Future Work}

Future research includes adding more disciplines, such as structural evaluation, using finite element analysis to evaluate the full potential of the framework. Also, strategies of how optimization can support the design in different stages of the building process: E.g., decision strategies regarding how to choose optimal solutions from the many Pareto solutions generated and how these solutions are affected by the different design variables.

Another opportunity for future research is to include more life-cycle energy details, such as scheduled maintenance. Adding more building components, apart from the building envelope, as well as home automation systems and energy production systems is also possible to get results that are more detailed. Including more design variables, e.g., building rotation, window to wall ratio, and envelope to floor area ratio, could also be of interest. The trade-off between investment cost and operational cost can also be of interest for future research to investigate at what point the application of additional energy efficiency measures (e.g., use of thicker insulations in the building envelope) stop being impactful.

Author Contributions: Funding acquisition, T.O.; Investigation, F.S.; Methodology, M.S. and J.M.; Supervision, M.S. and T.O.; Validation, F.S.; Writing—original draft, M.S., J.M. and F.S.; Writing-review \& editing, T.O.

Funding: This study is part of the Smart Built Environment project-Analysis of life-cycle properties in early design stages. The authors would like to thank FORMAS, the Swedish research council for sustainable development, for funding the study.

Acknowledgments: The authors would like to acknowledge NCC Construction Company for providing the data for the case study.

Conflicts of Interest: The authors declare no conflict of interest.

\section{References}

1. Eastman, C.; Teicholz, P.; Sacks, R.; Liston, K. BIM Handbook: A Guide to Building Information Modeling for Owners, Managers, Designers, Engineers and Contractors; John Wiley \& Sons: Hoboken, NJ, USA, 2011.

2. Khasreen, M.M.; Banfill, P.F.G.; Menzies, G.F. Life-cycle assessment and the environmental impact of buildings: A review. Sustainability 2009, 1, 674-701. [CrossRef]

3. Sandberg, M.; Tyapin, I.; Kokkolaras, M.; Lundbladh, A.; Isaksson, O. A knowledge-based master model approach exemplified with jet engine structural design. Comput. Ind. 2017, 85, 31-38. [CrossRef]

4. Díaz, H.; Alarcón, L.F.; Mourgues, C.; García, S. Multidisciplinary Design Optimization through process integration in the AEC industry: Strategies and challenges. Autom. Constr. 2017, 73, 102-119. [CrossRef]

5. Sacks, R.; Eastman, C.M.; Lee, G. Parametric 3D modeling in building construction with examples from precast concrete. Autom. Constr. 2004, 13, 291-312. [CrossRef]

6. Bouchlaghem, N.M.; Letherman, K.M. Numerical optimization applied to the thermal design of buildings. Build. Environ. 1990, 25, 117-124. [CrossRef]

7. Evins, R. A review of computational optimisation methods applied to sustainable building design. Renew. Sustain. Energy Rev. 2013, 22, 230-245. [CrossRef]

8. Abanda, F.H.; Vidalakis, C.; Oti, A.H.; Tah, J.H.M. A critical analysis of Building Information Modelling systems used in construction projects. Adv. Eng. Softw. 2015, 90, 183-201. [CrossRef]

9. Santos, R.; Costa, A.A.; Grilo, A. Bibliometric analysis and review of Building Information Modelling literature published between 2005 and 2015. Autom. Constr. 2017, 80, 118-136. [CrossRef]

10. Shadram, F.; Johansson, T.D.; Lu, W.; Schade, J.; Olofsson, T. An integrated BIM-based framework for minimizing embodied energy during building design. Energy Build. 2016, 128, 592-604. [CrossRef]

11. Mukkavaara, J. Structures for Supporting BIM-Based Automation in The Design Process; Luleå University of Technology: Luleå, Sweden, 2018; ISBN 9789177901846.

12. Miettinen, R.; Paavola, S. Beyond the BIM utopia: Approaches to the development and implementation of building information modeling. Autom. Constr. 2014, 43, 84-91. [CrossRef] 
13. Sandberg, M.; Gerth, R.; Lu, W.; Jansson, G.; Mukkavaara, J.; Olofsson, T. Design automation in construction: An overview. In Proceedings of the 33rd CIB W78 Conference 2016, Brisbane, Australia, 31 October-2 November 2016.

14. Newell, M.E.; Evans, D.C. Newell and Evans-Modeling by computer. In Proceedings of the IFIP Working Conference on Computer-Aided Design Systems, Austin, TX, USA, 12-14 October 1976; pp. 291-297.

15. Hoffman, C.M.; Joan-Arinyo, R. CAD and the product master model. CAD Comput. Aided Des. 1998, 30, 905-918. [CrossRef]

16. Monedero, J. Parametric design: A review and some experiences. Autom. Constr. 2000, 9, 369-377. [CrossRef]

17. Van Steen, M.; Tanenbaum, A.S. A brief introduction to distributed systems. Computing 2016, 98, 967-1009. [CrossRef]

18. Madiajagan, M. Interoperability in Component Based Software Development. Proc. World Acad. 2006, 2, 68-76.

19. Negendahl, K. Building performance simulation in the early design stage: An introduction to integrated dynamic models. Autom. Constr. 2015, 54, 39-53. [CrossRef]

20. Asl, R.M.; Zarrinmehr, S.; Bergin, M.; Yan, W. BPOpt: A framework for BIM-based performance optimization. Energy Build. 2015, 108, 401-412. [CrossRef]

21. Han, T.; Huang, Q.; Zhang, A.; Zhang, Q. Simulation-Based Decision Support Tools in the Early Design Stages of a Green Building-A Review. Sustainability 2018, 10, 3696. [CrossRef]

22. Lee, S.; Tae, S.; Roh, S.; Kim, T. Green template for life cycle assessment of buildings based on building information modeling: Focus on embodied environmental impact. Sustainability 2015, 7, 16498-16512. [CrossRef]

23. Liu, S.; Meng, X.; Tam, C. Building information modeling based building design optimization for sustainability. Energy Build. 2015, 105, 139-153. [CrossRef]

24. Kim, J.U.; Hadadi, O.A.; Kim, H.; Kim, J. Development of A BIM-based maintenance decision-making framework for the optimization between energy efficiency and investment costs. Sustainability 2018, 10, 2480. [CrossRef]

25. Flager, F.; Welle, B.; Bansal, P.; Soremekun, G.; Haymaker, J. Multidisciplinary process integration and design optimization of a classroom building. Electron. J. Inf. Technol. Constr. 2009, 14, 595-612. [CrossRef]

26. Ryu, H.S.; Park, K.S. A study on the LEED energy simulation process using BIM. Sustainability 2016, 8, 138. [CrossRef]

27. Zhang, J.; Michael Pelken, P.; Chen, Y.; Rice, D.J.; Meng, Z.; Semahegn, S.; Gu, L.; Henderson, H.; Feng, W.; Ling, F. "Virtual Design Studio"-Part 2: Introduction to overall and software framework. Build. Simul. 2013, 6, 253-268. [CrossRef]

28. Soust-Verdaguer, B.; Llatas, C.; García-Martínez, A. Critical review of bim-based LCA method to buildings. Energy Build. 2017, 136, 110-120. [CrossRef]

29. Gielingh, W. An assessment of the current state of product data technologies. CAD Comput. Aided Des. 2008, 40, 750-759. [CrossRef]

30. Emmerich, W. Software Engineering and Middleware: A Roadmap. In Proceedings of the Conference on The Future of Software Engineering, Limerick, Ireland, 4-11 June 2000. [CrossRef]

31. Toth, B.; Janssen, P.; Stouffs, R.; Chaszar, A.; Boeykens, S. Custom Digital Workflows: A New Framework for Design Analysis Integration. Int. J. Archit. Comput. 2012, 10, 481-499. [CrossRef]

32. Nguyen, A.T.; Reiter, S.; Rigo, P. A review on simulation-based optimization methods applied to building performance analysis. Appl. Energy 2014, 113, 1043-1058. [CrossRef]

33. Wright, J.A.; Loosemore, H.A.; Farmani, R. Optimization of building thermal design and control by multi-criterion genetic algorithm. Energy Build. 2002, 34, 959-972. [CrossRef]

34. Pareto, V. Course of Political Economy; Oxford University Press: Oxford, UK, 1896.

35. Gerrish, T.; Ruikar, K.; Cook, M.; Johnson, M.; Phillip, M.; Lowry, C. BIM application to building energy performance visualisation and managementChallenges and potential. Energy Build. 2017, 144, 218-228. [CrossRef]

36. Grasshopper. Available online: http://www.grasshopper3d.com/ (accessed on 3 January 2019).

37. Mirtschin, J. Geometry Gym IFC. Available online: https://github.com/jmirtsch/GeometryGymIFC (accessed on 3 January 2019).

38. Honeybee. Available online: https://www.ladybug.tools/ (accessed on 3 January 2019). 
39. Slingshot. Available online: http://wiki.theprovingground.org/slingshot (accessed on 3 January 2019).

40. Ahn, K.U.; Kim, Y.J.; Park, C.S.; Kim, I.; Lee, K. BIM interface for full vs. semi-automated building energy simulation. Energy Build. 2014, 68, 671-678. [CrossRef]

41. EnergyPlus. Available online: https://energyplus.net/ (accessed on 3 January 2019).

42. Deb, K. Multi-objective Genetic Algorithms: Problem Difficulties and Construction of Test Problems. Evol. Comput. 1999, 7, 205-230. [CrossRef] [PubMed]

43. Colorni, A.; Dorigo, M.; Maniezzo, V. Genetic algorithms and highly constrainedproblems: the time-table case. In Parallel Problem Solving from Nature; Schwefel, H., Männer, R., Eds.; Springer: Berlin, Germany, 1991.

44. Octopus. Available online: https://www.grasshopper3d.com/group/octopus (accessed on 3 January 2019).

45. Jo, J.H.; Gero, J.S. Space layout planning using an evolutionary approach. Artif. Intell. Eng. 1998, 12, $149-162$. [CrossRef]

46. Shadram, F.; Mukkavaara, J. An integrated BIM-based framework for the optimization of the trade-off between embodied and operational energy. Energy Build. 2018, 158, 1189-1205. [CrossRef]

47. Hammond, G.; Jones, C. Inventory of Carbon E Energy (ICE) Version 2.0; Sustainable Energy Research Team, Department of Mechanical Engineering, University of Bath: Bath, UK, 2012.

48. International EPD system. Environmental Product Declarations-Product Category Rules. Available online: http:/ / www.environdec.com/ (accessed on 3 January 2019).

49. EPD Norway. Available online: www.epd-norge.no (accessed on 3 January 2019).

50. Swedish District Heating Association. District Heating Local Environmental Values for 2015. Available online: http:/ / www.svenskfjarrvarme.se/In-English/District-Heating-in-Sweden/ (accessed on 3 January 2019).

51. Boverket (Swedish National Board of Housing, Building and Planning) Regulations and General Advice on Accessibility, Housing Design, Room Height, Operating Space, Fire Protection, Hygiene, Health and Environment, Noise Protection, Safety in Use and Energy. Available online: https://www. boverket.se/contentassets /a9a584aa0e564c8998d079d752f6b76d/konsoliderad_bbr_2011-6.pdf (accessed on 3 January 2019).

52. Hamdy, M.; Hasan, A.; Siren, K. A multi-stage optimization method for cost-optimal and nearly-zero-energy building solutions in line with the EPBD-recast 2010. Energy Build. 2013, 56, 189-203. [CrossRef]

53. Sveby, Standards for Energy in Buildings. Input Data for Calculation of Building's Energy Use. Available online: http:/ /www.sveby.org/wp-content/uploads/2012/10/Sveby_Brukarindata_bostader_version_1. 0.pdf (accessed on 3 January 2019).

54. Sweden's Central Bank, Real Interest Rate. Available online: https://www.riksbank.se/en-gb/ statistics/search-interest--\%0Aexchange-rates/explanation-of-the-series/riksbank-rates / (accessed on 3 January 2019).

(c) 2019 by the authors. Licensee MDPI, Basel, Switzerland. This article is an open access article distributed under the terms and conditions of the Creative Commons Attribution (CC BY) license (http://creativecommons.org/licenses/by/4.0/). 